\title{
The relationship between conservation of quantity and categorized free recall in primary-grade children
}

\author{
ELLIOTT W. SIMON \\ Emory University, Atlanta, Georgia 30322 \\ and \\ JOHN N. BOHANNON III \\ Georgia Institute of Technology, Atlanta, Georgia 30332
}

\begin{abstract}
Children in kindergarten $(n=31)$, first $(n=33)$, and second grade $(n=37)$ were assessed for conservation of quantity and were tested on categorized free recall of picture labels. An analysis of covariance determined that conservers recalled more items than nonconservers, independent of the effects of age, while older children recalled more items than younger children, independently of the ability to conserve. No relationship was observed between measures of output organization, clustering, and recall scores. It was concluded that both age and cognitive ability contribute to the development of memory.
\end{abstract}

The process of categorizing items to facilitate recall has been termed "memorializing" (Neimark, 1971). The development of memorializing skills is viewed as having an "ontogeny which ... is characteristic of all human beings and proceeds in an invariant sequence ...these changes in the nature of preliminary transformation of information underly [sic] the cognitive developmental stages described by Piaget (Neimark, 1971, p. 517). Neimark, Slotnick, and Ulrich (1971) did not test for developmental synchrony among their organizational or free recall measures and Piagetian measures of cognitive change. Their experiments admittedly led to this hypothesis and not vice versa.

There are two studies in the literature that compare memory performance with Piagetian assessments (Hanyes \& Kulhavy, 1976; Tomlinson-Keasey, Crawford, $\&$ Miser, 1975). Tomlinson-Keasey et al. examined the relationship of class-inclusion skills to organizational memory strategies in kindergarten and first-grade children. Classifiers recalled more and clustered significantly more than nonclassifiers.

Haynes and Kulhavy (1976) examined elementary and junior high school pupils for conservation level on three conservation tasks: mass, weight, and volume. Conservers and nonconservers were presented with a category free recall procedure. It was demonstrated that

This research was supported in part by Emory University Research Grant 8259 to the second author. The authors wish to express their thanks to Barbara and Paul Bianci and the students, teachers, and parents of the Paideia and Lullwater schools for their enthusiasm and cooperation during the course of this study. Reprint requests should be sent to J. N. Bohannon, III, School of Psychology, Georgia Institute of Technology, Atlanta, Georgia 30332. conservers remembered and clustered significantly more than nonconservers. It was concluded that "conservation level can be used as effectively as age to predict developmental trends in recall ... and that age related increases in recall can in part be due to differences in cognitive development" (Haynes \& Kulhavy, 1976, p. 183).

Age and conservation ability are confounded in the Haynes and Kulhavy (1976) study. It is well documented that free recall performance increases with age, as does performance on Piagetian measures. In order to make valid judgments concerning this relationship, the effect of age must be removed. The purpose of the present study is to determine whether the free recall/ conservation relationship remains once the age factor is removed by statistical methods.

\section{METHOD}

\section{Subjects}

The subjects were 101 middle class children, 31 kindergarteners (mean age $=67.8$ months), 33 first graders (mean age $=$ 79.4 months), and 37 second graders (mean age $=94.0$ months). There were 51 males and 50 females sampled from two private elementary schools.

\section{Procedure}

Two experimenters, one male and one female, administered both the Piagetian assessment and the memory measures. Subjects were tested by means of a double-blind procedure, with roughly half of the children run by each experimenter on each task. The order of presentation of the two measures was random across subjects.

\section{Memory Task}

The materials and procedure for the memory task were identical to those employed by Neimark et al. (1971). Twentyfour line drawings were prepared in 3-in. squares and laminated in plastic film. The pictures fell into four groups: animal, 
furniture, transportation, and clothing, each containing six pictures. An additional five pictures were prepared in the same manner and were presented in a practice trial.

Following the practice trial, children were asked to name each experimental picture; correction was given if a child failed to supply the proper name. After a 3-min study period, the experimenter collected the cards and the child's recall was recorded.

Three identical recall trials were given to each child. The number of items recalled and the amount of clustering present in a trial was calculated for each child. Clustering was calculated by use of the Moely, Olson, Halwes, and Flavell (1969) formula.

\section{Conservation of Quantity}

Each child was presented with two clay balls, each containing the same amount of clay, and was asked, "Does this [pointing to the right ball] have as much clay as this [pointing to the left ball] ?" If the child responded "no," the experimenter allowed the child to change the amount of clay in each ball until it was agreed that the amounts were equal. In view of the child, the experimenter flattened one of the balls into a pancake shape. The child was then asked, "Does this [pointing to the ball] have as much clay in it as this [pointing to the pancake]?" The same procedure was followed for two successive transformations, a sausage shape and a ring shape.

\section{RESULTS}

The effects of sex were tested in separate 2 (sex) by 3 (age) least-squares ANOVAs. There were no significant effects due to sex of child in Piagetian, recall, or clustering data. Therefore, the data were collapsed across sex for further analysis.

Children demonstrating conservation of quantity on all three trials were labeled conservers $\left(\mathrm{N}_{\mathrm{k}}=14\right.$, $\mathrm{N}_{1}=21, \mathrm{~N}_{2}=30$ ), the remaining children were labeled nonconservers $\left(\mathrm{N}_{\mathrm{k}}=17, \mathrm{~N}_{1}=12, \mathrm{~N}_{2}=7\right)$. This yielded 65 conservers and 36 nonconservers, with the effects of age and Piagetian stage confounded.

\section{Recall}

A confounded 2 (conservation) by 3 (trials) by 3 (grade) ANOVA revealed significant main effects of conservation $[\mathrm{F}(1,95)=6.71, \mathrm{p}<.01]$, trials $[F(2,190)=24.91, p<.01]$, and grade $[F(2,95)=7.03$, $\mathrm{p}<.01]$. This indicated that those children who demonstrated conservation recalled more items than nonconserving children. The Conservation by Trials interaction also attained significance $[F(2,190)=4.01$, $\mathrm{p}<.05$ ], indicating that conservers recalled more than nonconservers, a result identical with previous work (Haynes et al., 1976).

To correct for the confounding of age in the previous analysis, a 2 (conservation) by 3 (trials) by 3 (grade) analysis of covariance with age in months as the covariate was performed on the recall scores. Main effects of trials $[F(2,190)=24.91, p<.01]$ and conservation $[F(1,90)=4.67, p<.05]$ were revealed, with the Conservation by Trials interaction again attaining significance. To determine if increases in recall due to grade would remain once the effect of conservation ability was controlled, a 3 (grade) by 3 (trials) analysis of covariance was performed on the recall scores, using conservation as the covariate (a score of 0 or 1 was assigned to nonconserver and conserver, respectively). Main effects of grade $[\mathrm{F}(2,196)=7.60$, $\mathrm{p}<.01]$ and trials $[\mathrm{F}(2,196)=37.89, \mathrm{p}<.01]$ were revealed, with no significant interaction. Table 1 presents the mean recall scores for each trial along the dimensions of conserver-nonconserver and grade.

\section{Clustering}

The relationship among clustering, grade, trials, and conservation ability was determined by a 3 (grade) by 3 (trials) by 2 (conservation) least-squares split-plot ANOVA performed with the clustering scores. No significant main effects of grade, trials, or conservation, and no significant interactions were found. A Pearson correlation was performed between the total recall and total clustering scores, with a resulting correlation of -.007 .

\section{DISCUSSION}

A major hypothesis of this study was that the transition from nonconservation to conservation would be synchronous with increases in both clustering and number recalled. The recall data support the hypothesis and are in agreement with the contention of Neimark et al. (1971) and the results of Haynes et al. (1976). In Haynes' study, age and Piagetian stage were confounded; when age is removed from the data of the present investigation, the results are essentially those of Haynes. However, it also appears that increases in memory are not solely due to quantity conservation, as once this effect is removed, there are still significant memory increases across grade.

In the past (Moely et al., 1969; Neimark et al., 1971), memory increases such as those observed in this study have been attributed to an increase in the use of memory strategies,

Table 1

Number Recalled (NR) and Standard Deviations (SD) Across the Dimensions of Grade, Trials, and Conservation Ability

\begin{tabular}{|c|c|c|c|c|c|c|c|c|c|c|c|c|}
\hline \multirow[b]{3}{*}{ Trial } & \multicolumn{4}{|c|}{ Kindergarten } & \multicolumn{4}{|c|}{ First Grade } & \multicolumn{4}{|c|}{ Second Grade } \\
\hline & \multicolumn{2}{|c|}{$\begin{array}{c}\text { Nonconserver } \\
(n=17) \\
\end{array}$} & \multicolumn{2}{|c|}{$\begin{array}{l}\text { Conserver } \\
(n=14)\end{array}$} & \multicolumn{2}{|c|}{$\begin{array}{l}\text { Nonconserver } \\
(n=12)\end{array}$} & \multicolumn{2}{|c|}{$\begin{array}{l}\text { Conserver } \\
(n=21)\end{array}$} & \multicolumn{2}{|c|}{$\begin{array}{l}\text { Nonconserver } \\
(\mathrm{n}=7)\end{array}$} & \multicolumn{2}{|c|}{$\begin{array}{l}\text { Conserver } \\
(n=30)\end{array}$} \\
\hline & NR & SD & NR & SD & NR & SD & NR & SD & NR & SD & NR & SD \\
\hline 1 & 7.82 & 2.70 & 9.00 & 3.09 & 8.58 & 1.73 & 10.90 & 2.74 & 11.14 & 2.48 & 11.90 & 4.25 \\
\hline 2 & 7.65 & 3.14 & 10.57 & 4.78 & 9.83 & 3.21 & 11.62 & 4.59 & 13.57 & 4.08 & 13.80 & 5.27 \\
\hline 3 & 9.47 & 4.27 & 12.21 & 5.79 & 10.08 & 2.50 & 14.09 & 4.92 & 13.14 & 6.20 & 16.60 & 5.32 \\
\hline
\end{tabular}


specifically, clustering. The failure to find a relationship between conservation and clustering conflicts with this contention. Since the analysis of the clustering scores revealed no significant effects, evidence is provided that, at this age, organizational strategies may not be related to the qualitative cognitive changes involved in conservation acquisition.

An unexpected finding of the present study is the absence of a relationship between recall performance and clustering. If one examines more carefully the age range studied. in previously cited studies finding a relationship between clustering and number recalled, the present finding is less contradictory. Neimark et al. (1971) used subjects in a wide range (Grades 1, $3,4,5,6$, and college students), while the present investigation studied a more highly constricted range (kingergarten through Grade 2). When the results of Neimark's first-grade subjects are considered in isolation, there is no linear relationship between clustering and number recalled, while increases in memory over trials remain.

If free recall protocalls are not due to organization in children of this age, then what causes them? There are two hypotheses that may explain the lack of clustering in the present study. The first concerns the adequacy of available clustering measures. Schuell (1969) has reviewed the various extant measures and concluded that most have problems. Therefore, the children may organize their recall output, but the Moely et al. (1969) method does not measure it. The second hypothesis relates to the possibility that increases in recall may occur independent of organization. They may be due to differences in attention span, motivation, or many other factors known to increase with age. In light of this problem, the Neimark et al (1971) hypothesis may be reversed; advances in cognitive skill underlie the increasing recall observed with increasing age.

\section{REFERENCES}

Haynes, C. R., \& Kulhavy, R. W. Conservation level and category clustering. Developmental Psychology, 1976, 12, 179. 183.

Moely, B. E., Olson, F. A., Halwes, T. G., \& Flavell, J. H. Production deficiency in young children's clustered recall. Developmental Psychology, 1969, 1, 26-34.

NeImARK, E. An information processing approach to cognitive development. Transactions of the New York Academy of Sciences, 1971, 33, 516-528.

Neimark, E., Slotnick, N. S., \& Ulrich, T. Development of memorization strategies. Developmental Psychology, 1971, 5, 427-432.

Schuell, T. J. Clustering and organization in free recall. Psychological Bulletin, 1969, 72, 353-374.

Tomlinson-Keasey, C., Crawford, D. B., \& Miser, A. L. Classification: An organization operation for memory. Developmental Psychology, 1975, 11, 409-410.

(Received for publication August 18, 1978.) 